\title{
Urinary tract infections: Virulence factors, resistance to antibiotics, and management of uropathogenic bacteria with medicinal plants-A review
}

\author{
Mbarga Manga Joseph Arsene ${ }^{*}$ (D), Podoprigora Irina Viktorovna ${ }^{1}$ (D), Anyutoulou Kitio Linda Davares ${ }^{2}$ (D), \\ Ngah Esther $^{2}$ (D), Senyagin Alexander Nikolaevich ${ }^{1}$ \\ ${ }^{1}$ Department of Microbiology and Virology, Medical Institute, Peoples' Friendship University of Russia, Moscow, Russia. \\ ${ }^{2}$ Department of Food Sciences and Nutrition, National School of Agro-industrial Sciences, University of Ngaoundere, Ngaoundere, Cameroon.
}

\section{ARTICLE INFO \\ Received on: 24/01/2021 \\ Accepted on: 09/05/2021 \\ Available online: 05/07/2021}

\section{Key words: \\ Urinary tract infections, uropathogens, multidrug resistance, virulence factor antibacterial, phytochemicals, synergy, nanoparticles.}

\begin{abstract}
Urinary tract infections (UTIs) are among the most common infections in most countries and they are usually caused by the so-called uropathogenic (UP) microorganisms, including Escherichia coli (80\%-90\%), Staphylococcus aureus, Enterococcus faecalis, Pseudomonas aeruginosa, Proteus mirabilis, and Klebsiella pneumoniae. Over the years, the growth of resistance to antibiotics has complicated the treatment of UTIs and has direct consequences on the cost of treatment, the severity of infections, and the length of hospitalization. Medicinal plants, used for thousands of years to treat various diseases, constitute a serious alternative to antibiotics in the public health issue of antimicrobial resistance. In this review, the in vitro and in vivo use of medicinal plants and their nanoparticles (silver, gold, zinc, copper oxide, magnesium oxide, iron, etc.) in the management of uropathogens and their virulence factors (VFs) as well as in the management of UTIs themselves have been discussed. Given the advantages offered by the biologically active compounds of medicinal plants as well as their green-synthetized nanoparticles whether used as such or in combination with conventional antibiotics, it can be concluded that herbal medicine can significantly help in the management of UTIs.
\end{abstract}

\section{INTRODUCTION}

Urinary tract infections (UTIs) are very common infections in human population and can be defined as any infection, commonly of bacterial origin, which occurs in any part of the urinary system (Motse et al., 2019a). UTIs can be grouped as urethritis (localized in the urethra), cystitis (infection of the bladder), pyelonephritis (infection of the kidneys), and vaginitis (infection of the vagina) (Bissong et al., 2017; Fosso et al., 2017). Nowadays, UTIs are serious public health issues and are responsible for nearly 150 million disease cases every year worldwide (Motse et al., 2019a). 80\%-90\% of UTIs are caused by the so-called uropathogenic Escherichia coli (UPEC) (Abraham

\footnotetext{
*Corresponding Author

Mbarga Manga Joseph Arsene, Department of Microbiology and Virology, Medical Institute, Peoples' Friendship University of Russia, Moscow, Russia.E-mail: josepharsenembarga@yahoo.fr
}

et al., 2015; Ejrnaes et al., 2011), while 5\%-10\% are due to Staphylococcus saprophyticus (Nickel, 2008). These infections are rarely viral or fungal but can involve a much wider range of pathogens, especially Pseudomonas aeruginosa, Staphylococcus aureus, Klebsiella pneumoniae, Proteus mirabilis, Acinetobacter baumannii, Streptococcus, and Enterococcus faecalis (Amdekar et al., 2011; Flores-Mireles et al., 2015; Mann et al., 2017; Saka and Okunuga, 2017; Salvatore et al., 2011). UTIs are more likely to occur in women than men over all age groups (Abou Heidar et al., 2019) and up to 50\% of women report having had at least one urinary tract infection in their lifetime (Agarwal et al., 2020). These infections are usually treated with antibiotics (Abou Heidar et al., 2019). For acute uncomplicated UTIs, it is recommended to use trimethoprim-sulfamethoxazole (TMP-SMX), nitrofurantoin, or fosfomycin for 3-5 days (Gupta et al., 2011). However, high levels of resistance to TMP-SMX and ciprofloxacin preclude their use as empiric treatment for UTIs in patients who were previously exposed to them or who are at risk to be infected with extendedspectrum $\beta$-lactamases-(ESBLs-) producing bacteria (Bader 
et al., 2020). Second-line treatment is sometimes considered and usually includes oral cephalosporins (fluoroquinolones; cefixime) and $\beta$-lactams (amoxicillin-clavulanate) (Bader et al., 2020). In addition, depending on the case, other antibiotics may be used. However, notwithstanding the panoply of antimicrobials that can potentially be prescribed against UTIs, the problem of antibiotic resistance is also topical in UP strains. Indeed, in recent years, several studies have been carried out in different countries to assess the resistance to antibiotics of UP bacteria and the published results are clear. The resistance of UP strains is increasing, within some cases multidrug-resistant bacteria (MDR), and is not different from the global increase of the resistance to antibiotics observed around the world including all research areas (Dehbanipour et al., 2016; Karam et al., 2019; Kot, 2019; Lee et al., 2018; Mbarga et al., 2020, 2021; Motse et al., 2019b; Nzalie et al., 2016; Signing et al., 2020). Antibiotic resistance is a global issue that has led to a major mobilization in the search for new antimicrobial compounds and alternative ways of fighting bacterial infections. In this context, medicinal plants appear as a credible alternative (Wojnicz et al., 2012). Indeed, it is well known that plants have been used for millennia in the treatment and prevention of various diseases, including bacterial infections. Some of these herbal remedies have been shown to be effective in preventing and treating UTIs. Cranberries are one of the best-known products in this field. However, there are several other plants with wellknown antimicrobial properties which can contribute to the fight against antibiotic resistance in general and to the fight against uropathogens in particular (Wojnicz et al., 2012). The aim of this review is to discuss the plants commonly used to manage UTIs and particular importance is devoted to the mechanism of infections, host and risk factors in UTIs, uropathogens (UPs) themselves, their virulence factors (VFs), multidrug resistance issue, and a general view of the research carried out on the bacteriostatic and bactericidal properties of plant extracts on UPs.

\section{Review methodology}

This review article was done by exploiting numerous review articles, original articles, and related books from reputable databases, such as Web of Science, PubMed, and Scopus. The papers published with toll-access have been made available using the facilities provided by People's Friendship University of Russia, Moscow, Russia. The literature investigation process was conducted between October and December 2020 and the literature investigations were conducted in English and French. The keywords explored during literature searching consisted of combinations of the following words: "Urinary tract infections," "Uropathogenic bacteria," "Uropathogens," "Medicinal plants," "Herbal medicine," "Antimicrobial activity," "Infection du tractus urinaires," "Plantes médécinales," "Activité antibactérienne."

\section{Mechanism of infection}

\section{Ascending infection}

The bacteria most involved in UTIs are the same bacteria that colonize the intestine and enter the urinary tract after colonizing the periurethral region (Klein and Hultgren, 2020). The ascension of bacteria from the urethra to the bladder is the most common route of infection in UTIs (Walsh and Collyns, 2020).
It has been shown that if the bacteria were instilled directly into the bladder and a ureter was ligated, the unlit kidney was more likely to develop pyelonephritis (Walsh \& Collyns, 2020). Studies suggest that up to $95 \%$ of UTIs develop in an ascending fashion (Lane et al., 2007). In fact, the infection begins with periurethral colonization by UPs, then there is a migration to the bladder to establish the infection, and if the infection is not treated, there is an ascent to the upper urinary tract or ureters and kidneys. Once in the kidneys, UPEC can enter the bloodstream, causing bacteremia and sometimes death (Lane et al., 2007).

\section{Hematogenous infection}

This mode of contamination is infrequent. It assumes that UTIs can be a result of hematogenous spread of bacteria, for example, in prolonged bacteremia, often associated with a deep source of infection such as endocarditis (Walsh and Collyns, 2020). This mode of contamination has been demonstrated in animal models. One of the first studies on the subject, carried out by De Navasquez (1950), showed that the intravenous injection of $S$. aureus can cause pyelonephritis. However, a similar result was more difficult to achieve with Gram-negative bacteria, suggesting that this is not the common route of infection for most UTIs, since most of these infections are caused by Gram-negative bacteria, in particular UPECs (Motse et al., 2019a; Walsh and Collyns, 2020).

\section{Host and risk factors in UTIs}

Age and sex

The incidence of UTI is higher in women compared with men across all age groups. This is explained by the anatomy of women because, compared to men, their urethra is shorter and there is relative proximity between the urethra and the anus (Walsh and Collyns, 2020). The prevalence of UTIs among sexually active young women has been reported to vary from 0.5 to 0.7 per personyear, while this incidence rate among young men was only 0.01 (Rowe and Juthani-Mehta, 2013). However, the incidence of UTI decreases during middle age but rises in older adults. In addition, several other factors such as sexual intercourse and the use of spermicides have also been shown to increase the risk of UTI in women (Walsh and Collyns, 2020). In fact, spermicides affect the vaginal microbial flora, which leads to a reduction in lactobacilli and allows proliferation of potentially pathogenic bacteria in the genital tract (Walsh and Collyns, 2020). Furthermore, menopause can also significantly increase the risks of recurrent UTIs (Bleibel and Nguyen, 2020). Indeed, the reduction in estrogen levels can promote vaginal atrophy and lead to vaginal dryness and an increase in $\mathrm{pH}$, which alters the vaginal flora and also reduces the level of lactobacilli, then causing a proliferation of potentially pathogenic bacteria such as mentioned above.

\section{Structural abnormalities}

Recurrent UTIs can be favored by certain pathologies of the renal tract (Walsh and Collyns, 2020). These are particularly pathologies inducing a residual volume of urine postvoiding. Neurogenic bladder and vesicoureteric reflux are a good illustration of this phenomenon, as the protection of the unidirectional flow of urine is reduced and thus increases the risk of urinary tract infection. Kidney stones are also associated with UTIs and may 
even provide to bacteria a surface for biofilm formation (Walsh and Collyns, 2020). This pathology makes it difficult to eliminate bacteria through the flow of urine and more difficult to eradicate by the host's immune response due to the biofilms formed (Walsh and Collyns, 2020).

\section{Genetic factors}

The genetic hypothesis is often mentioned as a risk factor predisposing some people to UTIs. Indeed, Walsh and Collyns (2020) reported that women from families in which UTIs have been recorded are more prone to develop this infection. In addition, other parameters involving the genotypic aspect such as proteins that prevent bacterial adhesion (uroplakins; uromodulin), cells of the innate immune system (including neutrophils), and polymorphisms of various genes have been shown to be associated to recurrent UTIs. In addition, the decrease in certain IL-8 receptors such as CXCR1 and CXCR2 (which play a role in the recruitment of neutrophils) has been associated with recurrent UTIs in children. Finally, it has been established that CXCR2 levels are lower in women with recurrent UTIs than in controls (Walsh and Collyns, 2020).

\section{Catheterization}

The involvement of catheters or other urine drainage devices in the increased occurrence of recurrent urinary tract infection is well known, especially since they promote the formation of bacterial biofilms and provide a reservoir of potential pathogens in contact with the bladder (Rowe and Juthani-Mehta, 2013). Stickler (2014) demonstrated that almost all catheters in situ for more than 4 weeks become colonized with bacteria and Walsh and Collyns (2020) reported that if the biofilms formed are crystalline, they can block urine flow, exacerbating the problem.

\section{Microorganisms involved in UTIs, virulence factor, and MDR issue}

The microorganisms involved in UTIs are generally called uropathogens (UPs). Most UTIs are caused by E. coli (UPECs) and sometimes by other bacteria such as $S$. saprophyticus, $P$. aeruginosa, $S$. aureus, K. pneumoniae, P. mirabilis, Acinetobacter baumannii, Streptococcus, and E. faecalis or fungi such as Candida albicans (Amdekar et al., 2011; Mann et al., 2017; Saka and Okunuga, 2017; Salvatore et al., 2011). Nowadays, the growth of the resistance to antibiotics of UPs increasingly generates important complications in the management of UTIs (Sweileh et al., 2018). Indeed, numerous studies are carried out each year to evaluate the antibiotic resistance of UPs isolated from patients with UTIs and the results almost all indicate an increase of the antibioresistance over the years (Magyar et al., 2017; Sultan et al., 2015; Sweileh et al., 2018). In a study conducted in Hungary to assess the spectrum and antibiotic resistance of uropathogens between 2004 and 2015, Magyar et al. (2017) found that the five most commonly occurring bacteria were E. coli, E. faecalis, $K$. pneumoniae, $P$. aeruginosa, and $P$. mirabilis; and in this period, the resistance of $E$. coli to ciprofloxacin increased significantly from $19 \%$ to $25 \%$, resistance rates of $K$. pneumoniae to cephalosporins were very high (reaching 60\%), and they observed a significant increase in the rate of carbapenem-resistant P. aeruginosa (Magyar et al., 2017). In the same vein, Sweileh et al. (2018) conducted a global research on antimicrobial resistance in uropathogens using bibliometric analysis from 2002 to 2016. This study consisted of reviewing data provided by 1,087 articles (on antibiotic resistance of UPs) published in reference journals and they reported that increasing resistance of UPs is observed in different parts of the world. Otherwise, a parallel has been established between the pathogenicity, the VFs, and the resistance of UPs to antibiotics (Karam et al., 2018; Momtaz et al., 2013; Paniagua-Contreras et al., 2017; Rodriguez-Siek et al., 2005). Indeed, the pathogenicity of UPs is associated with the expression of several VFs, such as adhesion elements, toxins, capsules, flagella, serum resistance factors, and iron uptake systems (Rodriguez-Siek et al., 2005). In addition to their involvement in pathogenicity, several studies have revealed that there is a correlation between VFs and antibiotic resistance (Karam et al., 2018; Momtaz et al., 2013; PaniaguaContreras et al., 2017; Shah et al., 2019; Tabasi et al., 2015). Shah et al. (2019) reported that the comparison of MDR between UPEC-positive VF and UPEC negative VF showed significant differences $(69 \%$ vs. $16 \%, p=0.0001)$ and a comparative study of ESBLs also showed the same correlation. In a similar study conducted in Tehran (Iran), Karam et al. (2018) indicated that biofilm production is associated with antibiotic resistance and that iron receptors and hemolysin production also contribute to reduced antibiotic sensitivity of UPEC.

In general, in bacteria, whether they are UPs or not, several mechanisms such as changes in cell permeability and multiple efflux pumps, mutations of the antibiotic target, and horizontal transfer of resistance genes are responsible for the development of the antibiotic resistance (Fig. 1) (Mukherjee, 2019; Palma et al., 2020). However, despite the current knowledge on resistance to antibiotics and all the phenotypic observations, the mechanisms of the involvement of VFs in antibiotic resistance in UPs are not yet clearly identified (Alabsi et al., 2014). In a study carried out by Alabsi et al. (2014) to assess the association of some virulence genes with antibiotic resistance among UPEC isolated from UTI patients in Alexandria (Egypt), it has been established that there is a significant association between the presence of the pap gene and resistance to gentamicin but it was not significantly associated with resistance to TMP/SMX, aminoglycosides, nitrofurantoin, quinolones, and $\beta$-lactam antibiotics. Otherwise, there was no correlation between the genes $s f a$, aer, and $c n f l$ and UPEC resistance to any antibiotics; and Alabsi et al. (2014) finally concluded that resistance of UPEC could be attributed to other VFs. In the same vein, without establishing the mechanism of the implication of VFs in antibiotics resistance, Raeispour and Ranjbar (2018) also concluded that UPEC strains causing infections are more likely to harbor certain virulence genes.

Finally, no research published in reference journals provides precise information on the specific mechanisms of the implication of VFs in antibiotic resistance but it is clear that this correlation is well existing. Studies should be carried out in this direction because in-depth knowledge of these mechanisms could guide towards new therapies for the prevention of UTIs and the fight against resistance of UPs to antibiotics. Otherwise, more globally, to overcome this problem of resistance which has real consequences in the management of UTIs (complications of the treatment, the continuity of the transmission chain of resistance genes between UPs and between Ups, and other commensal or 


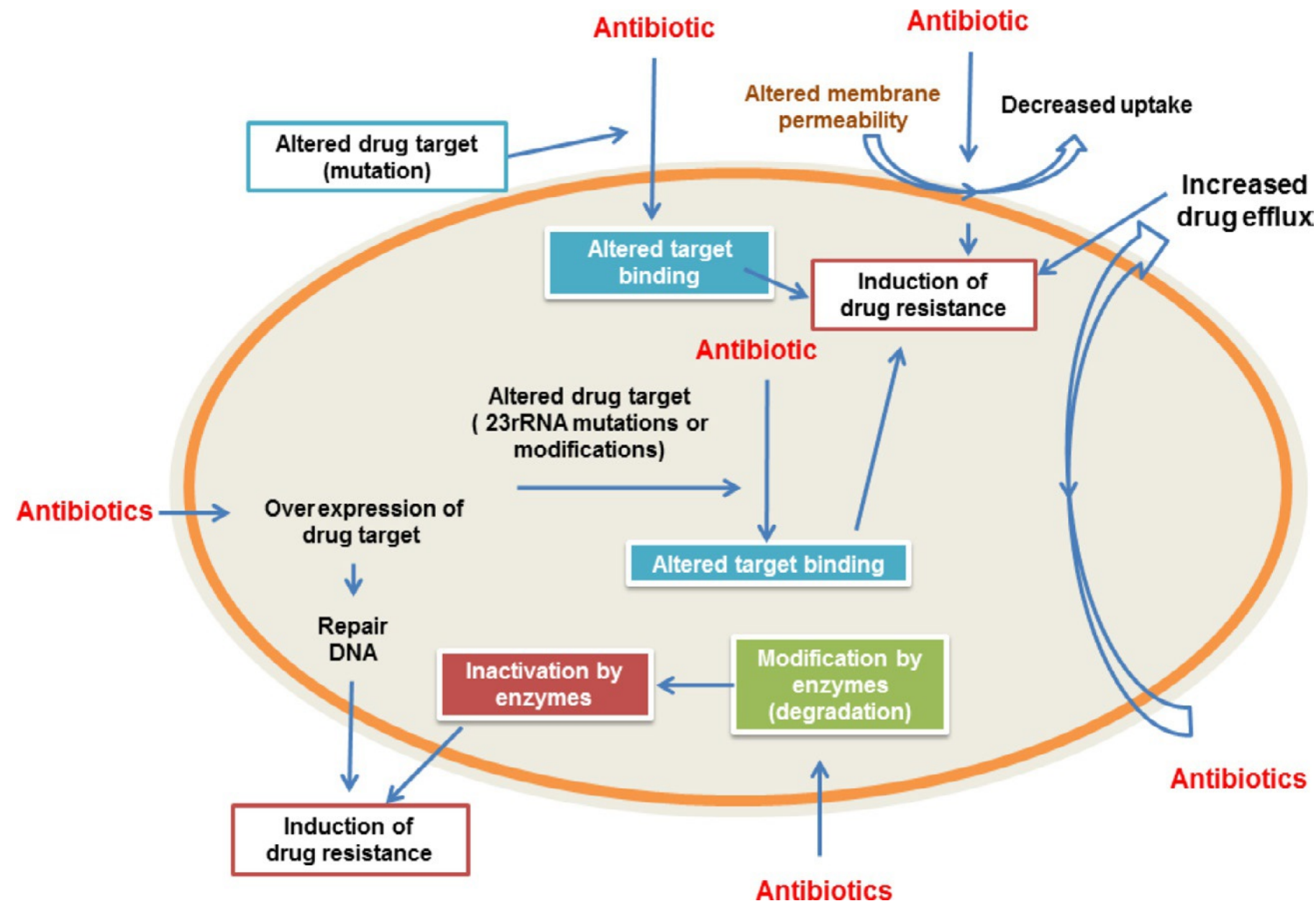

Figure 1. Mechanisms of antimicrobial resistance (Mukherjee, 2019).

pathogenic bacteria), it became necessary to search for new antimicrobial molecules against UPs, including phytochemicals, green-synthesized nanoparticles, and even a potential combination of phytochemicals and conventional antibiotics.

Use of plants extract, phytochemicals, and green-synthetized nanoparticles against UTIs and UPs

The use of medicinal plants in the treatment and prevention of various diseases including UTIs is a very ancient practice (Shaheen et al., 2019). Due to easy availability, fewer reported side effects, cost-effectiveness, tolerance towards the patients with UTIs, and lack of bacterial resistance, herbal remedies are regaining more and more popularity and reliability worldwide (Shaheen et al., 2019). Given the growth of resistance to antibiotics, more and more researchers are assessing the antibacterial properties of various plants and their constituents. Indeed, according to search engines like Google Scholar, before the year 2000, only 4,290 concerning UTIs and medicinal plants were published while between 2000 and 2020 more than 17,300 articles were published on the same topic. A similar increase has been observed with modern databases such as PubMed, Scirus, ScienceDirect, and Scopus. Most of these researches are carried out in vitro to determine the effectiveness of the antibacterial activity of specific plant extracts against UPs, to isolate the active phytocompounds, to green-synthesize nanoparticles and test their antibacterial properties on UPs, to study the synergy between the plant extracts and conventional antibiotics, and to determine the minimum inhibitory concentration (MIC) and bactericidal inhibitory concentration (MBC).

Table 1 shows MIC and MBC of some plants against specific UP strains. These studies show that MICs and MBCs vary depending on the medicinal plants and the UP strains on which the extracts were tested. Indeed, a lower MIC value indicates that less drug is required for inhibiting the growth of the microorganism; therefore, plants with lower MICs such as methanolic leaves extracts of Amaranthus tricolor (against UPEC, MIC $=0.36 \mathrm{mg}$ / $\mathrm{ml}$; and $K$. pneumoniae, $\mathrm{MIC}=0.62 \mathrm{mg} / \mathrm{ml}$ ) (Sowjanya et al., 2015), Anogeissus acuminata (against $S$. aureus; $\mathrm{MIC}=0.67 \mathrm{mg}$ / $\mathrm{ml}$ ) (Sowjanya et al., 2015), and Cassia tora (against E. faecalis, $\mathrm{MIC}=0.67 \mathrm{mg} / \mathrm{ml}$ ) (Mishra and Padhy, 2013) could be more advantageous in terms of efficacy and harmlessness since, for a possible standardization of their use, optimum efficacy could be obtained by administering small amounts of extract. However, further studies should be conducted to confirm the validity of such a hypothesis under in vivo conditions and in the treatment of UTIs. 
Table 1. MIC and MBC of some plants with antibacterial properties against specific uropathogens.

\begin{tabular}{|c|c|c|c|c|}
\hline Uropathogens & Antibacterial plants/part used/solvent & $\mathrm{MIC}(\mathrm{mg} / \mathrm{ml})$ & $\operatorname{MBC}(\mathbf{m g} / \mathbf{m l})$ & Reference \\
\hline \multirow[t]{4}{*}{ E. coli } & Mentha piperita/leaf/EthOH & 125 & - & Pulipati et al., 2016 \\
\hline & A. tricolor/leaf/MethOH & 0.36 & - & Sowjanya et al., 2015 \\
\hline & Anthocephalus cadamba/bark/MethOH & 9.63 & 21.67 & Mishra and Padhy, 2013 \\
\hline & C. tora/leaf/MethOH & 4.27 & 9.63 & Mishra and Padhy, 2013 \\
\hline \multirow[t]{5}{*}{ E. faecalis } & A. tricolor/leaf/MethOH & 2.5 & - & Sowjanya et al., 2015 \\
\hline & C. tora/leaf/MethOH & 0.67 & 1.51 & Mishra and Padhy, 2013 \\
\hline & Albizia lebbeck/leaf/MethOH & 9.63 & 21.67 & Mishra and Padhy, 2013 \\
\hline & A. acuminata/leaf $\mathrm{MethOH}$ & 0.67 & 1.51 & Mishra and Padhy, 2013 \\
\hline & A. cadamba/bark/MethOH & 3.41 & 4.27 & Mishra and Padhy, 2013 \\
\hline \multirow[t]{3}{*}{ P. mirabilis } & A. acuminata/leaf $/ \mathrm{MethOH}$ & 4.27 & 9.63 & Mishra and Padhy, 2013 \\
\hline & C. tora/leaf/MethOH & 3.41 & 4.27 & Mishra and Padhy, 2013 \\
\hline & A. cadamba/bark/MethOH & 4.27 & 9.63 & Mishra and Padhy, 2013 \\
\hline \multirow[t]{4}{*}{ P. aeruginosa } & M. piperita/leaf/EthOH & 125 & - & Pulipati et al., 2016 \\
\hline & A. tricolor/leaf/MethOH & 1.25 & - & Sowjanya et al., 2015 \\
\hline & A. acuminata/leaf/MethOH & 1.51 & 3.41 & Mishra and Padhy, 2013 \\
\hline & Artocarpus heterophyllus/bark/MethOH & 9.63 & 9.63 & Mishra and Padhy, 2013 \\
\hline \multirow[t]{4}{*}{ K. pneumoniae } & M. piperita/leaf/EthOH & 125 & - & Pulipati et al., 2016 \\
\hline & A. acuminata/leaf/MethOH & 4.27 & 9.63 & Mishra and Padhy, 2013 \\
\hline & A. cadamba/bark/MethOH & 9.63 & 21.67 & Mishra and Padhy, 2013 \\
\hline & A. tricolor/leaf/MethOH & 0.62 & - & Sowjanya et al., 2015 \\
\hline \multirow[t]{5}{*}{ S. aureus } & M. piperita/leaf/EthOH & 62.5 & - & Pulipati et al., 2016 \\
\hline & A. acuminata/leaf/MethOH & 0.67 & 1.51 & Mishra and Padhy, 2013 \\
\hline & A. cadamba/bark/MethOH & 1.51 & 3.41 & Mishra and Padhy, 2013 \\
\hline & A. heterophyllus/bark/MethOH & 9.63 & 9.63 & Mishra and Padhy, 2013 \\
\hline & C. tora/leaf $/ \mathrm{MethOH}$ & 1.51 & 3.41 & Mishra and Padhy, 2013 \\
\hline S. saprophyticus & A. tricolor/leaf/MethOH & 5.0 & - & Sowjanya et al., 2015 \\
\hline
\end{tabular}

The exact mechanism of the herbal drugs used to treat UTIs is not yet fully understood, but studies have shown that plant constituents and secondary metabolites actas diuretics, antioxidants, immunomodulators, and antimicrobials, preventing the fixation of pathogens in the urinary tract and stopped the proliferation of microorganisms (Shaheen et al., 2019). These diverse properties of medicinal plants are due to the presence of various phytochemical constituents including secondary metabolites as presented in Table 2. However, with regard specifically to the bacteriostatic and bactericidal effect of plant extracts, it has been established that phytochemicals act either by using the usual mechanisms of conventional antibiotics (by inhibiting the synthesis of the bacterial wall, by action on membrane cells, by inhibition of nucleic acid synthesis, by inhibition of protein synthesis, or by inhibition of folate metabolism) or by inhibition of efflux pumps (Khosravani et al., 2020). The inhibition of efflux pumps has various advantages in this age of antibiotic resistance (Sadeq Abdulridha et al., 2020). Indeed, efflux pumps allow bacteria to flush antibiotics out of bacterial cells and therefore reduce their sensitivity to conventional antibiotics. Thus, the inhibition of these pumps would make bacteria, including MDR bacteria, more sensitive to conventional antibiotics, and would make it possible to suppress resistance to antibiotics while reducing MICs (Sadeq Abdulridha et al., 2020).

Some plants well known in various countries of the world such as cranberries (Vaccinium oxycoccos and Vaccinium macrocarpon) and blueberries (Vaccinium corymbosum), both from the Ericaceae family, are widely used medicinal plants in the treatment of UTIs (Saeed, 2010; Shaheen et al., 2019). Numerous studies have reported the effectiveness of cranberry and blueberry in prevention and treatment of UTIs (Sadeq Abdulridha et al., 2020; Shaheen et al., 2019; Tempera et al., 2010; Wojnicz et al., 2012). The anti-UTI effects of cranberries and blueberries are attributed to fructose and proanthocyanidins (PACs) which inhibit VFs such as $\mathrm{P}$ fimbria by preventing pathogens from colonizing the urinary tract. Indeed, as shown in Figure 2, the type 1 fimbriae which is sensitive to mannose is blocked by fructose and PACs block the others type 1 fimbria mannose-resistant: this reduces the adhesion capacity of the bacteria and enables the bladder to "flush out" the UPs when urine is expelled (Sihra et al., 2018). In addition, randomized controlled trials have shown that cranberry juice can reduce the 


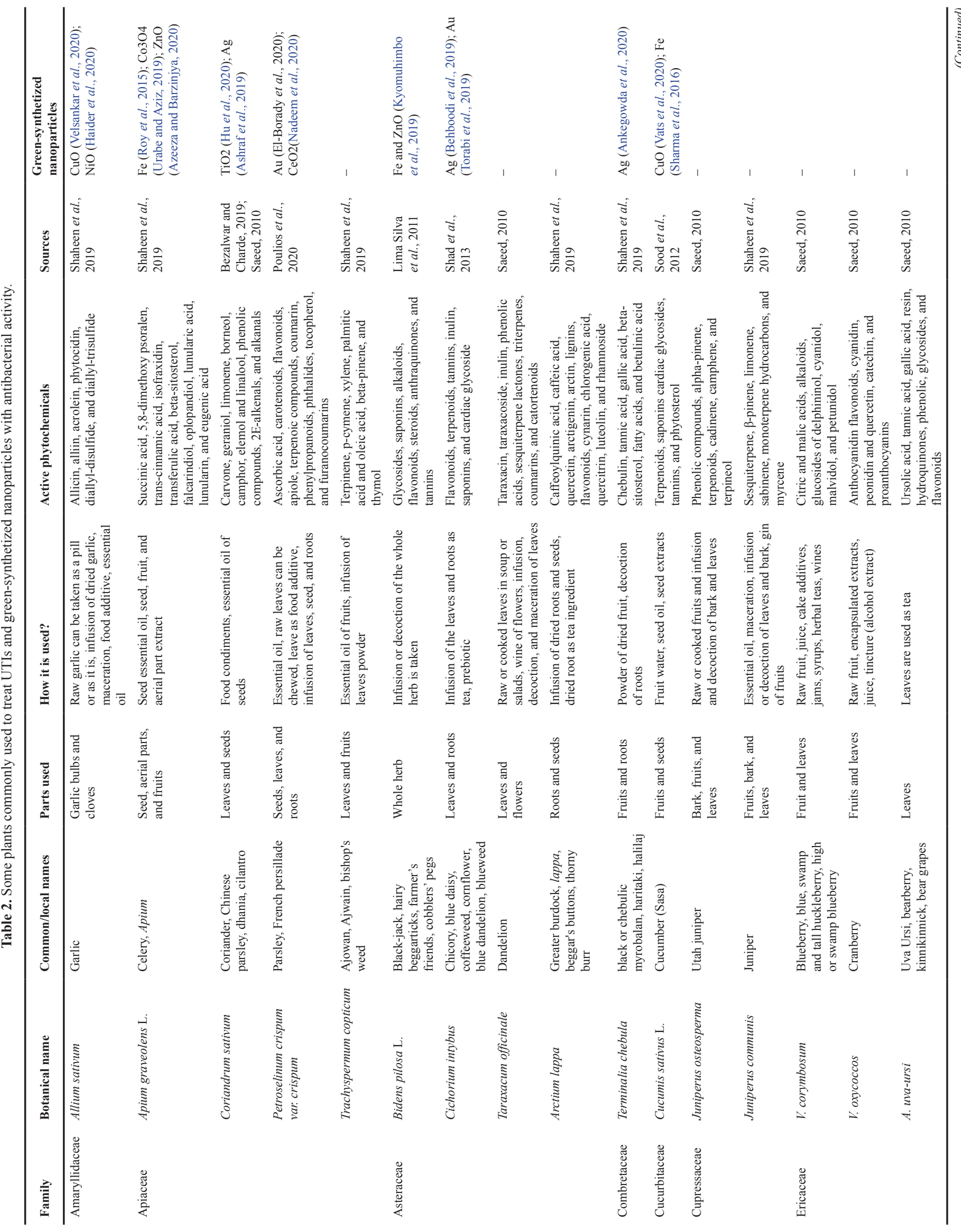




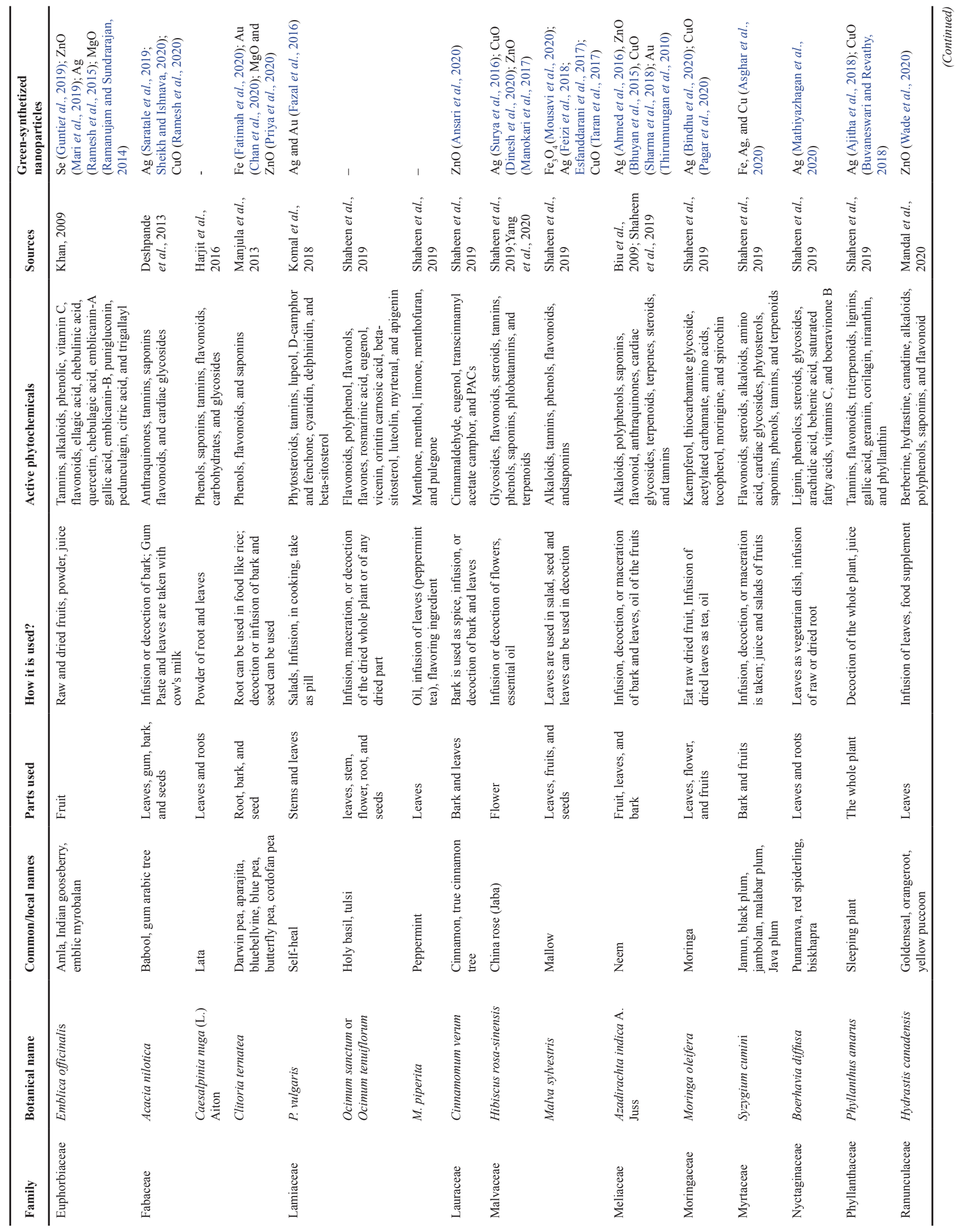




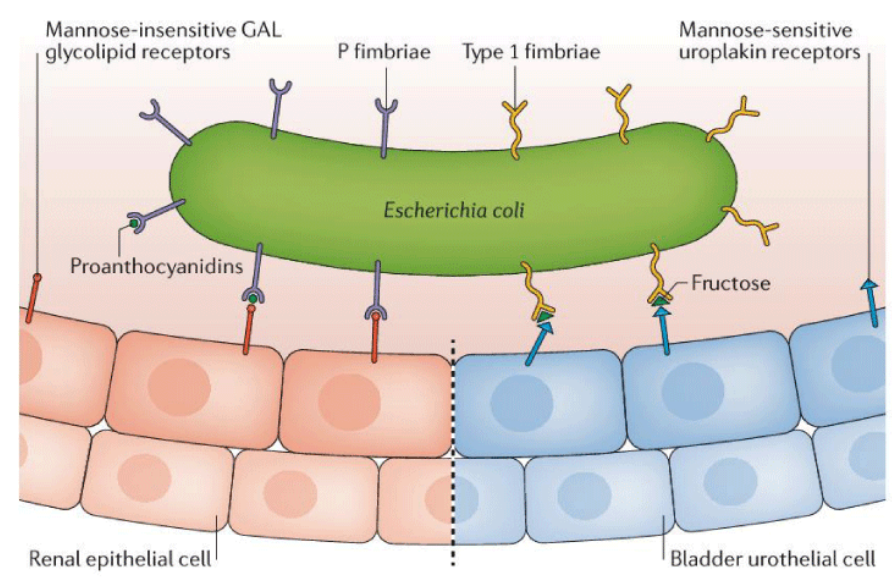

Figure 2. Mechanisms of action of antiadhesive activity of cranberry. PACs bind P fimbriae and prevent it from binding to mannose-insensitive GAL glycolipid receptors (renal epithelial cells). Fructose binds to type 1 fimbriae, preventing it from binding to mannose-sensitive uroplakin receptors (bladder epithelial cells) (Sadeq Abdulridha et al., 2020; Sihra et al., 2018).

number of symptomatic UTIs over a 12 months period in women with recurrent UTIs (Saeed, 2010). Nowadays, the cranberries and blueberries products are marketed in the form of capsules, pills, juice, syrup, and lozenges.

Arctostaphylos uva-ursi (Uva Ursi, Bearberry), another plant from the Ericaceae family, is also well known in the treatment of UTIs (Sadeq Abdulridha et al., 2020; Saeed, 2010). Gohari and Saeidnia (2014) reported that the Uva Ursi was shown to be effective on bacterial inflammatory diseases in general when used at the rate of $3 \mathrm{~g}$ of infusion of the dried herb, 4 times daily. In addition, the use of leaf extracts of Uva Ursi has been authorized in some countries such as Germany (by German Federal Institute for Drugs and Medical Devices) for the management of UTIs (Sadeq Abdulridha et al., 2020; Saeed, 2010). The antimicrobial effect of Uva Ursi is attributed to arbutin which is metabolized into hydroquinone whose antimicrobial and antioxidant properties are well known (Sadeq Abdulridha et al., 2020).

Several in vivo and in vitro studies confirmed that the extracts of Hydrastis canadensis (Goldenseal) have antibacterial activity towards Gram-positive UPs, including methicillinresistant Staphylococcus aureus, due to alkaloid compounds such as berberine, hydrastine, and canadine, which has antibacterial activity against Gram-positive pathogens (Mandal et al., 2020; Sadeq Abdulridha et al., 2020). Otherwise, other plant extracts like rosemary (Rosmarinus officinalis) have been found to be effective against UPs such as E. coli, P. mirabilis, Prunella vulgaris, $K$. pneumoniae, P. aeruginosa, and S. aureus (Sadeq Abdulridha et al., 2020). However, not being able to discuss the characteristics and individual effects of each of the plants commonly used in the prevention and treatment of UTIs, we have proposed to group together in Table 2 the plants commonly used to manage this pathology, of which the efficacy has been reported in the literature. This table includes the family of the plant, scientific name, usual name, the parts used, the way of using them, the phytochemicals that constitute it, and the nanoparticles which have been greensynthesized and which have demonstrated antimicrobial skills. 


\section{CONCLUSION}

UTIs are very common in most countries of the world and very current in women and the elderly. The treatment of these pathologies which uses conventional antibiotics is increasingly hard given the growing resistance to antibiotics. This review presented some plants known for their effectiveness in the management of UTIs. Medicinal plants have various advantages because they are safe, economical, and easy to use and their main advantage is that bacteria have not yet developed resistance against them. Notwithstanding the above, additional studies must be carried out to study and discuss the molecules responsible for the efficacy of these plants against UTIs, to understand the mechanisms of involvement of VFs in antibiotic resistance, and to standardize the use of different plant extracts that do not yet have legal authorization in the countries where they are used to be taken against UTIs. Finally, large randomized, double-blind clinical studies need to be conducted on each of these plants and their secondary metabolites to provide more evidence on the clinical efficacy and safety of these products.

\section{ACKNOWLEDGMENTS}

This publication has been supported by the RUDN University Strategic Academic Leadership Program.

\section{CONFLICT OF INTEREST}

The authors have declared that no competing interests exist.

\section{ETHICAL APPROVALS}

Not applicable.

\section{PUBLISHER'S NOTE}

This journal remains neutral with regard to jurisdictional claims in published institutional affiliation.

\section{REFERENCES}

Abou Heidar NF, Degheili JA, Yacoubian AA, Khauli RB. Management of urinary tract infection in women: A practical approach for everyday practice. Urol Ann, 2019; 11(4):339.

Abraham SN, Miao Y. The nature of immune responses to urinary tract infections. Nat Rev Immunol, 2015; 15(10):655.

Agarwal DK, Krambeck AE, Sharma V, Maldonado FJ, Westerman ME, Knoedler JJ, Rivera ME. Treatment of non-obstructive, non-struvite urolithiasis is effective in treatment of recurrent urinary tract infections. World J Urol, 2020; 38(8):2029-33.

Ahmed S, Saifullah, Ahmad M, Swami BL, Ikram S. Green synthesis of silver nanoparticles using Azadirachta indica aqueous leaf extract. J Radiat Res Appl Sci, 2016; 9(1):1-7.

Ahmeda A, Zangeneh A, Zangeneh MM. Green synthesis and chemical characterization of gold nanoparticle synthesized using Camellia sinensis leaf aqueous extract for the treatment of acute myeloid leukemia in comparison to daunorubicin in a leukemic mouse model. Appl Organomet Chem, 2020; 34(3):e5290

Ajitha B, Reddy YAK, Jeon HJ, Ahn CW. Synthesis of silver nanoparticles in an eco-friendly way using Phyllanthus amarus leaf extract: antimicrobial and catalytic activity. Adv Powder Technol, 2018; 29(1):86-93.

Akbarian M, Mahjoub S, Elahi SM, Zabihi E, Tashakkorian H. Appraisal of the biological aspect of Zinc oxide nanoparticles prepared using extract of Camellia sinensis L. Mater Res Express, 2019; 6(9):095022.

Alabsi MS, Ghazal A, Sabry SA, Alasaly MM. Association of some virulence genes with antibiotic resistance among uropathogenic Escherichia coli isolated from urinary tract infection patients in Alexandria, Egypt: a hospital-based study. J Glob Antimicrob Resist, 2014; 2(2):83-6.
Amdekar S, Singh V, Singh DD. Probiotic therapy: immunomodulating approach toward urinary tract infection. Curr Microbiol, 2011; 63(5):484.

Ankegowda VM, Kollur SP, Prasad SK, Pradeep S, Dhramashekara C, Jain AS, Prasad A, Srinivasa C, Sridhara Setty PB, Gopinath SM, Prasad SR, Bahkali AH, Syed A, Shivamallu C. Phytomediated synthesis of silver nanoparticles using Terminalia chebula fruit extract and evaluation of its cytotoxic and antimicrobial potential Molecules, 2020; 25(21):5042.

Ansari MA, Murali M, Prasad D, Alzohairy MA, Almatroudi A, Alomary MN, Udayashankar AC, Singh SB, Asiri SMM, Ashwini BS, Gowtham HG, Kalegowda N, Amruthesh KN, Lakshmeesha TR, Niranjana SR. Cinnamomum verum bark extract mediated green synthesis of $\mathrm{ZnO}$ nanoparticles and their antibacterial potentiality. Biomolecules, 2020; 10(2):336.

Asghar MA, Zahir E, Asghar MA, Iqbal J, Rehman AA. Facile, one-pot biosynthesis and characterization of iron, copper and silver nanoparticles using Syzygium cumini leaf extract: as an effective antimicrobial and aflatoxin B1 adsorption agent. PloS One, 2020; 15(7):e0234964.

Ashraf A, Zafar S, Zahid K, Shah MS, Al-Ghanim KA, AlMisned F, Mahboob S. Synthesis, characterization, and antibacterial potential of silver nanoparticles synthesized from Coriandrum sativum L. J Infect Public Health, 2019; 12(2):275-81.

Azeeza HH, Barzinjya AA. Biosynthesis zinc oxide nanoparticles using Apium graveolens L. leaf extract and its use in removing the organic pollutants in water. Desalination Water Treat, 2020; 190:179-92.

Bader MS, Loeb M, Leto D, Brooks AA. Treatment of urinary tract infections in the era of antimicrobial resistance and new antimicrobia agents. Postgrad Med, 2020; 132(3):234-50.

Behboodi S, Baghbani-Arani F, Abdalan S, Shandiz SAS Green engineered biomolecule-capped silver nanoparticles fabricated from Cichorium intybus extract: in vitro assessment on apoptosis properties toward human breast cancer (MCF-7) cells. Biol Trace Elem Res, 2019; 187(2):392-402.

Bezalwar PM, Charde VN. Study on synergistic action of Coriandrum sativum seed extracts on antibiotics against multidrug resistant P. aeruginosa. Environ Conserv J, 2019; 20(3):83-8.

Bhuyan T, Mishra K, Khanuja M, Prasad R, Varma A Biosynthesis of zinc oxide nanoparticles from Azadirachta indica for antibacterial and photocatalytic applications. Mater Sci Semicond Process, $2015 ; 32: 55-61$.

Bindhu MR, Umadevi M, Esmail GA, Al-Dhabi NA, Arasu MV. Green synthesis and characterization of silver nanoparticles from Moringa oleifera flower and assessment of antimicrobial and sensing properties. J Photochem Photobiol B, 2020; 205:111836.

Bissong MEA, Mbah C, Tatsing Foka F, Kamga HL. Spectrum of uropathogens and antimicrobial susceptibility in clinically diagnosed cases of urinary tract infection in the Bamenda regional hospital, Cameroon. Am J Health Res, 2017; 5(2):19-24.

Biu AA, Yusufu SD, Rabo JS. Phytochemical screening of Azadirachta indica (Neem) (Meliaceae) in Maiduguri, Nigeria. Biosci Res Commun, 2009; 21(6):281-3.

Bleibel B, Nguyen H. Vaginal atrophy. StatPearls, Treasure Island, FL, 2020. Available via https://www.ncbi.nlm.nih.gov/books/ NBK559297/

Buvaneswari K, Revathy R. Biosynthesis of copper oxide nanoparticles and its antimicrobial activities. J Nanosci Technol, 2018; 4(4):450-1.

Chan JZ, Rasit Ali R, Shameli K, Salleh MSN, Lee KX, Isa ED Green synthesis of gold nanoparticles using aqueous extract of Clitoria ternatea flower. IOP Conf Ser Mater Sci Eng, 2020; 808(1):012036.

De Navasquez, S. Experimental pyelonephritis in the rabbit produced by staphylococcal infection. J Pathol Bacteriol, 1950; 62(3):429-36.

Dehbanipour R, Rastaghi S, Sedighi M, Maleki N, Faghri J. High prevalence of multidrug-resistance uropathogenic Escherichia coli strains, Isfahan, Iran. J Nat Sci Biol Med, 2016; 7(1): 22. 
Deshpande SN. Preliminary phytochemical analysis and in vitro investigation of antibacterial activity of Acacia nilotica against clinical isolates. J Pharmacogn Phytochem, 2013; 1(5):23.

Dinesh GK, Pramod M, Chakma S. Sonochemical synthesis of amphoteric $\mathrm{Cu} 0$-nanoparticles using Hibiscus rosa-sinensis extract and their applications for degradation of 5-fluorouracil and lovastatin drugs. $\mathrm{J}$ Hazard Mater, 2020; 399:123035.

Ejrnaes K, Stegger M, Reisner A, Ferry S, Monsen T, Holm SE, Lundgren B, Frimodt-Moller N. Characteristics of Escherichia coli causing persistence or relapse of urinary tract infections: phylogenetic groups, virulence factors and biofilm formation. Virulence 2011; 2:528-37.

El-Borady OM, Ayat MS, Shabrawy MA, Millet P. Green synthesis of gold nanoparticles using Parsley leaves extract and their applications as an alternative catalytic, antioxidant, anticancer, and antibacterial agents. Adv Powder Technol, 2020; 31(10):4390-400.

El-Shenawy NS, Hamza RZ, Al-Salmi FA, Al-Eisa RA. Evaluation of the effect of nanoparticles zinc oxide/Camellia sinensis complex on the kidney of rats treated with monosodium glutamate: antioxidant and histological approaches. Curr Pharm Biotechnol, 2019; 20(7):542-50.

Esfanddarani, H. M., Kajani, A. A., \& Bordbar, A. K. Green synthesis of silver nanoparticles using flower extract of Malva sylvestris and investigation of their antibacterial activity. IET nanobiotechnol, 2017; 12(4):412-6.

Fatimah I, Hidayat H, Nugroho BH, Husein S. Ultrasoundassisted biosynthesis of silver and gold nanoparticles using Clitoria ternatea flower. S Afr J Chem Eng, 2020; 34:97-106.

Fazal H, Abbasi BH, Ahmad N, Ali M. Elicitation of medicinally important antioxidant secondary metabolites with silver and gold nanoparticles in callus cultures of Prunella vulgaris L. Appl Biochem Biotechnol, 2016; 180(6):1076-92.

Feizi S, Taghipour E, Ghadam P, Mohammadi P. Antifungal, antibacterial, antibiofilm and colorimetric sensing of toxic metals activities of eco friendly, economical synthesized $\mathrm{Ag} / \mathrm{AgCl}$ nanoparticles using Malva sylvestris leaf extracts. Microb Pathog, 2018; 125:33-42.

Flores-Mireles AL, Walker JN, Caparon M, Hultgren SJ. Urinary tract infections: epidemiology, mechanisms of infection and treatment options. Nat Rev Microbiol, 2015; 13(5):269-84.

Fosso JAM, Njouendou AJ, Ekom SE, Kengne IC. Antibacterial activity of three Cameroonian medicinal plants traditionally used for the treatment of urinary tract infections and their synergistic effects with amoxicillin and serum. J Adv Med Pharm Sci, 2017; 15(2):1-14.

Gohari AR, Saeidnia S. The role of herbal medicines in treatment of urinary tract diseases. J Nephropharmacol, 2014; 3(1):13.

Gunti L, Dass RS, Kalagatur NK. Phytofabrication of selenium nanoparticles from Emblica officinalis fruit extract and exploring its biopotential applications: antioxidant, antimicrobial, and biocompatibility. Front Microbiol, 2019; 10:931.

Gupta K, Hooton TM, Naber KG, Wullt B, Colgan R, Miller LG, Moran GJ, Nicolle LE, Raz R, Schaeffer AJ, Soper DE, Infectious Diseases Society of America, European Society for Microbiology and Infectious Diseases. International clinical practice guidelines for the treatment of acute uncomplicated cystitis and pyelonephritis in women: a 2010 update by the Infectious Diseases Society of America and the European Society for Microbiology and Infectious Diseases. Clin Infect Dis, 2011; 52(5):e103-20.

Haider A, Ijaz M, Ali S, Haider J, Imran M, Majeed H, Shahzadi I, Ali MM, Khan JA, Ikram M. Green synthesized phytochemically (Zingiber officinale and Allium sativum) reduced nickel oxide nanoparticles confirmed bactericidal and catalytic potential. Nanoscale Res Lett, 2020; 15(1):1-11.

Hamidi A, Yazdi MET, Amiri MS, Hosseini HA, Darroudi M. Biological synthesis of silver nanoparticles in Tribulus terrestris L. extract and evaluation of their photocatalyst, antibacterial, and cytotoxicity effects. Res Chem Intermediates, 2019; 45(5):2915-25.

Harjit K, Amini MH, Suttee A. (2016). Evaluation of antioxidant and anthelmintic properties of Caesalpinia sappan L. leaves. Int J Pharmacogn Phytochem Res, 2016; 8:362-8.
Hu J, Wu X, Wu F, Chen W, White JC, Yang Y, Wang B, Xing B, Tao S, Wang X. Potential application of titanium dioxide nanoparticles to improve the nutritional quality of coriander (Coriandrum sativum L.). J Hazard Mater, 2020; 389:121837.

Karam MRA, Habibi M, Bouzari S. Relationships between virulence factors and antimicrobial resistance among Escherichia coli isolated from urinary tract infections and commensal isolates in Tehran, Iran. Osong Public Health Res Perspect, 2018; 9(5):217.

Karam MRA, Habibi M, Bouzari S. Urinary tract infection: pathogenicity, antibiotic resistance and development of effective vaccines against uropathogenic Escherichia coli. Mol Immunol, 2019; 108:56-67.

Khan KH. Roles of Emblica officinalis in medicine-a review. Bot Res Int, 2009; 2(4):218-28.

Kheirabadi Z, Mehrabani M, Sarafzadeh F, Dabaghzadeh F, Ahmadinia N. Green tea as an adjunctive therapy for treatment of acute uncomplicated cystitis in women: a randomized clinical trial. Complement Ther Clin Pract, 2019; 34:13-6.

Khosravani M, Dallal MMS, Norouzi M. Phytochemical composition and anti-efflux pump activity of hydroalcoholic, aqueous, and hexane extracts of artemisia tournefortiana in ciprofloxacin-resistant strains of Salmonella enterica serotype enteritidis. Iran J Public Health, 2020; 49(1):134

Klein RD, Hultgren SJ. Urinary tract infections: microbial pathogenesis, host-pathogen interactions and new treatment strategies. Nat Rev Microbiol, 2020; 18(4):211-26.

Komal S, Kazmi SAJ, Khan JA, Gilani MM. Antimicrobial activity of Prunella vulgaris extracts against multi-drug resistant Escherichia coli from patients of urinary tract infection. Pak J Med Sci, 2018; 34(3):616

Kot B. Antibiotic resistance among uropathogenic Escherichia coli. Pol J Microbiol, 2019; 68(4):403.

Kyomuhimbo HD, Michira IN, Mwaura FB, Derese S, Feleni U, Iwuoha EI. Silver-zinc oxide nanocomposite antiseptic from the extract of Bidens pilosa. SN Appl Sci, 2019; 1(7):681.

Lane MC, Alteri CJ, Smith SN, Mobley HL. Expression of flagella is coincident with uropathogenic Escherichia coli ascension to the upper urinary tract. Proc Natl Acad Sci, 2007; 104(42):16669-74.

Lee DS, Lee SJ, Choe HS. Community-acquired urinary tract infection by Escherichia coli in the era of antibiotic resistance. Biomed Res Int, 2018; 2018:7656752.

Lima Silva F, Fischer DCH, Fechine Tavares J, Sobral Silva M, Filgueiras de Athayde-Filho P, \& Barbosa-Filho JM. Compilation of secondary metabolites from Bidens pilosa L. Molecules, 2011; 16(2):1070-102.

Magyar A, Köves B, Nagy K, Dobák A, Arthanareeswaran VKA, Bálint P, Wagenlehner F, Tenke P. Spectrum and antibiotic resistance of uropathogens between 2004 and 2015 in a tertiary care hospital in Hungary. J Med Microbiol, 2017; 66(6):788-97.

Mandal SK, Maji AK, Mishra SK, Ishfaq PM, Devkota HP, Silva AS, Das N. Goldenseal (Hydrastis canadensis L.) and its active constituents: a critical review of their efficacy and toxicological issues. Pharmacol Res, 2020; 160:105085.

Manjula P, Mohan CH, Sreekanth D, Keerthi B, Devi BP. Phytochemical analysis of Clitoria ternatea Linn., a valuable medicina plant. J Indian Bot Soc, 2013; 92(3and4):173-8.

Mann R, Mediati DG, Duggin IG, Harry EJ, Bottomley AL. Metabolic adaptations of uropathogenic E. coli in the urinary tract. Front Cell Infect Microbiol, 2017; 7:241.

Manokari M, Shekhawat MS. Biosynthesis of zinc oxide nanoparticles from the aerial parts of Hibiscus rosa-sinensis L. J Sci Achiev, 2017; 2(5):1-6.

Mari A, Mookkaiah R, Elayaperumal M. Emblica officinalis leaf extract mediated synthesis of zinc oxide nanoparticles for antibacterial and photocatalytic activities. Asian J Green Chem, 2019; 3(4):418-31.

Mathiyazhagan M, Raj JJ, Gabriel JJ. Characterization and antimicrobial properties of biofabricated silver nanoparticles using different extracts of Boerhavia diffusa L. Adv Sci Eng Med, 2020; 12(4):530-4.

Mbarga MJA, Desobgo SCZ, Tatsadjieu LN, Kavhiza N, Kalisa L. Antagonistic effects of raffia sap with probiotics against 
pathogenic microorganisms. Foods Raw Mater, 2021; 9(1):24-31; doi:10.21603/23084057-2021-1-24-31

Mbarga MMJ, Andreevna SL, Viktorovna PI. Evaluation of apparent microflora and study of antibiotic resistance of coliforms isolated from the shells of poultry eggs in Moscow-Russia. J Adv Microbiol, 2020; 20(4):70-7.

Mbarga MJA, Desobgo SCZ, Tatsadjieu LN, Kavhiza N, Kalisa L. Antagonistic effects of raffia sap with probiotics against pathogenic microorganisms. Foods Raw Mater, 2021; 9(1):24-31.

Mishra MP, Padhy RN. In vitro antibacterial efficacy of 21 Indian timber-yielding plants against multidrug-resistant bacteria causing urinary tract infection. Osong Public Health Res Perspect, 2013; 4(6):347-57.

Momtaz H, Karimian A, Madani M, Dehkordi FS, Ranjbar R, Sarshar M, Souod N. Uropathogenic Escherichia coli in Iran: serogroup distributions, virulence factors and antimicrobial resistance properties. Ann Clin Microbiol Antimicrob, 2013; 12(1):8.

Motse DFK, Ngaba GP, Foko LPK, Ebongue CO, Adiogo DD. Etiologic profile and sensitivity pattern of germs responsible for urinary tract infection among under-five children in Douala, Cameroon: a HospitalBased Study. Avicenna J Clin Microbiol Infect, 2019a; 6(2):49-56.

Motse DFK, Ngaba GP, Kojom LP, Koum DCK, Okalla CE, Penda CI, Mah E, Andreas C, Adiogo DD. Predictors of urinary tract infection and their diagnostic performances among Cameroonian underfive. J Microbiol Infect Dis, 2019b; 9(02):68-77.

Mousavi SM, Hashemi SA, Zarei M, Bahrani S, Savardashtaki A, Esmaeili H, Lai CW, Mazraedoost S, Abassi M, Ramavandif B. Data on cytotoxic and antibacterial activity of synthesized $\mathrm{Fe} 3 \mathrm{O} 4$ nanoparticles using Malva sylvestris. Data Brief, 2020; 28:104929.

Mukherjee PK. Quality control and evaluation of herbal drugs: evaluating natural products and traditional medicine. Elsevier, Amsterdam, Netherlands, 2019.

Nadeem M, Khan R, Afridi K, Nadhman A, Ullah S, Faisal S, Ul Mabood Z, Hano C, Abbasi BH. Green synthesis of cerium oxide nanoparticles ( $\mathrm{CeO} 2 \mathrm{NPs})$ and their antimicrobial applications: a review. Int J Nanomedicine, 2020; 15:5951-61.

Nickel, JC. Inflammation and benign prostatic hyperplasia. Urol Clin North Am, 2008; 35(1):109-15.

Nzalie RNT, Gonsu HK, Koulla-Shiro S. Bacterial etiology and antibiotic resistance profile of community-acquired urinary tract infections in a Cameroonian city. Int J Microbiol, 2016; 2016:3240268.

Pagar K, Ghotekar S, Pagar T, Nikam A, Pansambal S, Oza R, Sanap D, Dabhane, H. Antifungal activity of biosynthesized $\mathrm{CuO}$ nanoparticles using leaves extract of Moringa oleifera and their structural characterizations. Asian J Nanosci Mater, 2020; 3(1):15-23.

Palma E, Tilocca B, Roncada P. Antimicrobial resistance in veterinary medicine: an overview. Int J Mol Sci, 2020; 21(6):1914.

Paniagua-Contreras GL, Monroy-Pérez E, RodríguezMoctezuma JR, Domínguez-Trejo P, Vaca-Paniagua F, Vaca S. Virulence factors, antibiotic resistance phenotypes and O-serogroups of Escherichia coli strains isolated from community-acquired urinary tract infection patients in Mexico. J Microbiol Immunol Infect, 2017; 50(4):478-85.

Poulios E, Vasios GK, Psara E, Giaginis C. Medicinal plants consumption against urinary tract infections: a narrative review of the current evidence. Expert Rev Anti Infect Ther, 2020; 19(4):519-28.

Priya P, Elumali K, Shakila D, Geetha K, Karthik AD. Facile approach to synthesize, compared to $\mathrm{MgO} \& \mathrm{ZnO}$ nanoparticles by using Clitoria ternatea/Tecoma castanifolia flower. Mater Today, 2020; 29:1217-22.

Pulipati S, Koushik OS, Babu P. Phytochemical analysis and antibacterial efficacy of Mentha piperita (L) ethanolic leaf extract against clinical isolates of uropathogens. Microbiol Res J Int, 2016; 13(6):1-5.

Raeispour M, Ranjbar R. Antibiotic resistance, virulence factors and genotyping of uropathogenic Escherichia coli strains. Antimicrob Resist Infect Control, 2018; 7(1):118

Ramanujam K, Sundrarajan M. Antibacterial effects of biosynthesized $\mathrm{MgO}$ nanoparticles using ethanolic fruit extract of Emblica officinalis. JPhotochem Photobiol, 2014; 141:296-300.
Ramesh PS, Kokila T, Geetha D. Plant mediated green synthesis and antibacterial activity of silver nanoparticles using Emblica officinalis fruit extract. Spectrochim Acta A, 2015; 142:339-43.

Ramesh S, Vinitha UG, Anthony SP, Muthuraman MS. Pods of Acacia nilotica mediated synthesis of copper oxide nanoparticles and it's in vitro biological applications. Mater Today, 2020.

Rodriguez-Siek KE, Giddings CW, Doetkott C, Johnson TJ, Fakhr MK, Nolan LK. Comparison of Escherichia coli isolates implicated in human urinary tract infection and avian colibacillosis. Microbiology, 2005; 151(6):2097-110.

Rowe TA, Juthani-Mehta M. Urinary tract infection in older adults. Aging Health, 2013; 9(5):519-28.

Roy K, Sarkar CK, Ghosh CK. Apium graveolens leaf extractmediated synthesis of silver nanoparticles and its activity on pathogenic fungi. Dig J Nanomater Biostruct, 2015; 10:393-400.

Sadeq Abdulridha GK, Raghad Abdulatif A, Khetam Habeeb R, Salam Ali K. Western herbal remedies for Urinary Tract infections. Arch Urol Res, 2020; 4(1): 49-60.

Saeed S. Herbal remedies for urinary tract infection. Int J Biol Biotechnol, 2010; 7(4):347-52.

Saka SA, Okunuga BE. Profiling urinary tract infections bacteria among elderly population in a Nigerian Teaching Hospital. J Med Biomed Sci, 2017; 6(3):15-22.

Salvatore S, Salvatore S, Cattoni E, Siesto G, Serati M, Sorice P, Torella M. Urinary tract infections in women. Eur J Obstet Gynecol Reprod Biol, 2011; 156(2):131-6.

Saratale RG, Saratale GD, Cho SK, Ghodake G, Kadam A, Kumar S., Mulla SI, Dong-Su K, Byong-Hun J, Jo Shu C, Shin HS. Phytofabrication of silver nanoparticles by Acacia nilotica leaves: investigating their antineoplastic, free radical scavenging potential and application in $\mathrm{H}_{2} \mathrm{O}_{2}$ sensing. J Taiwan Inst Chem Eng, 2019; 99:239-49.

Shad MA, Nawaz H, Rehman T, Ikram N. Determination of some biochemicals, phytochemicals and antioxidant properties of different parts of Cichorium intybus L.: a comparative study. J Anim Plant Sci, 2013; 23(4):1060-6.

Shah C, Baral R, Bartaula B, Shrestha LB. Virulence factors of uropathogenic Escherichia coli (UPEC) and correlation with antimicrobial resistance. BMC Microbiol, 2019; 19(1):204.

Shaheen G, Akram M, Jabeen F, Ali Shah SM, Munir N, Daniyal M, Zainab R. Therapeutic potential of medicinal plants for the management of urinary tract infection: a systematic review. Clin Exp Pharmacol Physiol, 2019; 46(7):613-24.

Sharma BK, Shah DV, Roy DR. Green synthesis of $\mathrm{CuO}$ nanoparticles using Azadirachta indica and its antibacterial activity for medicinal applications. Mater Res Express, 2018; 5(9):095033.

Sharma K, Kaushik S, Jyoti A. Green synthesis of silver nanoparticles by using waste vegetable peel and its antibacterial activities. J Pharm Sci Res, 2016; 8(5):313.

Sheikh KI, Ishnava KB. Biosynthesis of silver nanoparticles from Acacia nilotica (L.) Wild. Ex. Delile Leaf Extract. In: Gupta VK, Srivastava N, Srivastava M, Mishra PK (eds.). Green synthesis of nanomaterials for bioenergy applications, Wiley, Hoboken, NJ, pp 145-63, 2020.

Signing AT, Marbou WJT, Beng VP, Kuete V. Antibiotic resistance profile of uropathogenic bacteria in diabetic patients at the Bafoussam Regional Hospital, West Cameroon Region. Cureus, 2020; 12(7):e9345.

Sihra N, Goodman A, Zakri R, Sahai A, Malde S. Nonantibiotic prevention and management of recurrent urinary tract infection. Nat Rev Urol 2018; 15:750-76.

Sood A, Kaur P, Gupta R. Phytochemical screening and antimicrobial assay of various seeds extract of Cucurbitaceae family. Int J Appl Biol Pharm Technol, 2012; 3(3):401-9.

Sowjanya P, Babu PS, Narasu ML. Phytochemical analysis and antibacterial efficacy of Amaranthus tricolor (L) methanolic leaf extract against clinical isolates of urinary tract pathogens. Afr J Microbiol Res, 2015; 9(20):1381-5. 
Stickler DJ. Clinical complications of urinary catheters caused by crystalline biofilms: something needs to be done. J Intern Med, 2014; 276(2):120-9.

Sultan A, Rizvi M, Khan F, Sami H, Shukla I, Khan HM. Increasing antimicrobial resistance among uropathogens: is fosfomycin the answer? Urol Ann, 2015; 7(1):26.

Surya S, Kumar GD, Rajakumar R. Green synthesis of silver nanoparticles from flower extract of Hibiscus rosa-sinensis and its antibacterial activity. Int J Innov Res Sci Eng Technol, 2016; 5:5242-7.

Sweileh WM, Al-Jabi SW, Sa'ed HZ, Sawalha AF, Abu-Taha AS. Global research output in antimicrobial resistance among uropathogens: a bibliometric analysis (2002-2016). J Glob Antimicrob Resist, 2018; 13:104-14.

Tabasi M, Karam MRA, Habibi M, Yekaninejad MS, Bouzari $\mathrm{S}$. Phenotypic assays to determine virulence factors of uropathogenic Escherichia coli (UPEC) isolates and their correlation with antibiotic resistance pattern. Osong Public Health Res Perspect, 2015; 6(4):261-8.

Taran M, Rad M, Alavi M. Antibacterial activity of copper oxide $(\mathrm{CuO})$ nanoparticles biosynthesized by Bacillus sp. FU4: optimization of experiment design. Pharm Sci, 2017; 23(3):198-206.

Tempera G, Corsello S, Genovese C, Caruso FE, Nicolosi D. Inhibitory activity of cranberry extract on the bacterial adhesiveness in the urine of women: an ex-vivo study. Int J Immunopathol Pharmacol, 2010; 23:611-8

Thirumurugan A, Jiflin GJ, Rajagomathi G, Tomy NA, Ramachandran S, Jaiganesh R. Biotechnological synthesis of gold nanoparticles of Azadirachta indica leaf extract. Int J Biol Technol, 2010; $1: 75-7$.

Torabi N, Nowrouzi A, Ahadi A, Vardasbi S, Etesami B. Green synthesis of gold nanoclusters using seed aqueous extract of Cichorium intybus L. and their characterization. SN Appl Sci, 2019; 1(9):981.

Urabe AA, Aziz WJ. Biosynthesis of cobalt oxide (Co3O4) nanoparticles using plant extract of Camellia sinensis (L.) Kuntze and Apium graveolens L. as the antibacterial application. World News Nat Sci, $2019 ; 24: 357-65$.

Varghese B, Kurian M, Krishna S, Athira TS. Biochemical synthesis of copper nanoparticles using Zingiber officinalis and Curcuma longa: characterization and antibacterial activity study. Mater Today, 2020; 25(2):302-6.

Vats M, Bhardwaj S, Chhabra A. Green synthesis of copper oxide nanoparticles using Cucumis sativus (cucumber) extracts and their biophysical and biochemical characterization for cosmetic and dermatologic applications. Endocr Metab Immune Disord Drug Targets, 2020; 21(4): $726-33$.

Velsankar K, RM AK, Preethi R, Muthulakshmi V, Sudhahar S Green synthesis of $\mathrm{CuO}$ nanoparticles via Allium sativum extract and its characterizations on antimicrobial, antioxidant, antilarvicidal activities. J Environ Chem Eng, 2020; 8(5):104123.

Wade EA, Massie CJ, Harris DF. Synthesis and characterization of $\mathrm{ZnO}$ nanoparticles from extracts of Allium sativum and Hydrastis canadensis. In Conference: Virtual Idaho Conference on Undergraduate Research (ICUR). Idaho, 2020.

Walsh C, Collyns T. The pathophysiology of urinary tract infections. Surgery (Oxf), 2020; 38(4):191-6.

Wojnicz D, Kucharska AZ, Sokół-Łętowska A, Kicia M, Tichaczek-Goska D. Medicinal plants extracts affect virulence factors expression and biofilm formation by the uropathogenic Escherichia coli. Urol Res, 2012a; 40(6):683-97.

Wojnicz D, Sycz Z, Walkowski S, Gabrielska J, Włoch A, Kucharska A, Anna S, Hendrich AB. Study on the influence of cranberry extract_Zuravit on the properties of uropathogenic Escherichia coli strains, their ability to form biofilm and its antioxidant properties. Phytomedicine 2012b; 19:506-14.

Yang X, Rajivgandhi GN, Ramachandran G, Alharbi NS, Kadaikunnan S, Khaled JM, Almanaa TN, Manoharan N, Viji R. Preparative HPLC fraction of Hibiscus rosa-sinensis essential oil against biofilm forming Klebsiella pneumoniae. Saudi J Biol Sci, 2020; 27(10):2853-62.

How to cite this article:

Arsene MMJ, Viktorovna PI, Davares AKL, Esther N, Nikolaevich SA. Urinary tract infections: Virulence factors, resistance to antibiotics, and management of uropathogenic bacteria with medicinal plants - A review. J Appl Pharm Sci, 2021; 11(07):001-012. 